\title{
Probing the Characteristic Deformation Behaviors of Transformation-Induced Plasticity Steels
}

\author{
SHENG CHENG, XUN-LI WANG, ZHILI FENG, BJORN CLAUSEN, HAHN CHOO, \\ and PETER K. LIAW
}

\begin{abstract}
The characteristic micromechanical behaviors of contrasting transformation-induced plasticity (TRIP) steels were investigated under tensile loading by in-situ neutron diffraction and transmission electron microscopy in detail. As demonstrated by the lattice strain development from the neutron diffraction, in the TRIP steel with $\sim 10$ pct RA, microyielding of soft ferrite was responsible for the first stress partition, but a second stress sharing was caused by effective martensitic transformation. In the TRIP steel with less than 5 pct RA, where the contribution from the martensitic transformation was minor, stress partition took place virtually between the ferrite and bainite phase. Probing with systematic transmission electron microscopy (TEM) observations, we pin down the inherent correlation between the microstructural evolutions and the stress partition mechanism. Based on the experimental observations, the factors influencing the work-hardening behavior of TRIP steels are discussed.
\end{abstract}

DOI: $10.1007 / \mathrm{s} 11661-008-9604-4$

(C) The Minerals, Metals \& Materials Society and ASM International 2008

\section{INTRODUCTION}

WITH increasing demands for materials with good comprehensive mechanical properties, transformationinduced plasticity (TRIP) steels have attracted much attention in recent years. ${ }^{[1-5]}$ The TRIP steels are expected to have an excellent combination of high strength and tensile ductility due to their improved work-hardening ability. ${ }^{[6]}$ It is well known that workhardening ability in a single-phase alloy is often dictated by dislocation pinning/tangling and multiplication. ${ }^{[7]}$ However, as the dislocation density accumulates to a certain degree, dynamic recovery occurs, and then further hardening becomes difficult. The TRIP steels use a totally different hardening mechanism as opposed to dislocation multiplication. The TRIP steels normally contain a metastable phase, e.g., retained austenite (RA), which transforms into martensite under applied load. As the strength of martensite is much higher than its austenite parent, the strain-induced martensitic transformation work hardens the material, thus ensuring a high ductility. ${ }^{[8,9]}$ In addition, as the mechanically-

SHENG CHENG, Postdoctoral Research Associate, HAHN CHOO, Associate Professor, and PETER K. LIAW, Professor, are with the Department of Materials Science and Engineering, the University of Tennessee, Knoxville, TN, 37996. Contact e-mail: scheng1@utk.edu XUN-LI WANG, Instrument Scientist, Neutron Scattering Sciences Division, and ZHILI FENG, Staff Scientist, Materials Science and Technology Division, are with the Oak Ridge National Laboratory. BJORN CLAUSEN, Instrument Scientist, is with the Los Alamos Neutron Science Center, Los Alamos National Laboratory, Los Alamos, NM, 87545.

This article is based on a presentation given in the symposium entitled "Neutron and X-Ray Studies for Probing Materials Behavior," which occurred during the TMS Spring Meeting in New Orleans, LA, March 9-13, 2008, under the auspices of the National Science Foundation, TMS, the TMS Structural Materials Division, and the TMS Advanced Characterization, Testing, and Simulation Committee. Article published online August 5, 2008 induced martensite introduces a volume expansion during transformation, this geometrical change has an effect of strain hardening the surrounding ferrite matrix at the microscopic level. Consequently, the failure due to necking is shifted to a higher strain. However, in addition to RA, multiple phases are usually present in TRIP steels due to the thermomechanical processing, which renders the deformation of TRIP steels very complicated. So far great effort was devoted to optimizing the thermomechanical processing parameters for improved mechanical properties, ${ }^{[10-14]}$ but the influence of strain-induced martensitic transformation in TRIP steels on the work-hardening behavior was not well understood. In particular, the micromechanical character of individual phase on the work-hardening process in TRIP steels was far from being well explored due to the complexity from the multiple phases. As the strength of the co-existing phases is quite different, their micromechanical response to applied stress is different. ${ }^{[15]}$ Especially after a martensitic transformation is induced, substantial stress redistribution takes place between phases, i.e., the stress partitioning. ${ }^{[16-18]}$ Because the stress partitioning process actually reflects the relative phase hardening, a critical assessment of the real-time stress partitioning process is thus crucial to understanding the hardening process. In recent years, the rapid development of characterization techniques such as high-energy X-ray diffraction or neutron diffraction has made the real-time measurements possible. ${ }^{[19-22]} \mathrm{On}$ the other hand, due to the fact that the ferrite and martensite in TRIP steels are of body-centered structure (such that the diffraction peaks from these phases overlap), and bainite consists of alternating plates of austenite and ferrite (some carbides and martensite can also exist) in TRIP steel, the interpretation of the stress partition from $X$-ray and neutron diffraction of these phases is often difficult..$^{[5,23,24]}$ To obtain a full 
understanding of the hardening behavior, additional methods are necessary to characterize all the constitutive phases. In this article, we not only aim to probe the hardening mechanism of TRIP steels from the perspective of their stress partition behavior by in-situ neutron diffraction, but also examine the individual phase by detailed transmission electron microscopy (TEM) studies during deformation. By measuring the lattice strain evolutions of both product and parent phases, we expected to shed a light on the hardening mechanism of TRIP steels. The TEM is employed to provide insightful evidence in elucidating lattice strain evolution, as well as the correlation with respect to the stress partition and hardening behavior.

\section{EXPERIMENTAL}

Two TRIP steels with contrasting mechanical properties were chosen for this study: TRIP 590 and TRIP 780. The former has a higher volume fraction of RA, and the latter less RA. The chemical compositions of these TRIP steels are shown in Table I. These TRIP steels have great potentials for automobile industry due to their good energy consumption capacity. ${ }^{[25]}$ They are more cost effective than stainless steels and their deformation behaviors are also very different. ${ }^{[26-28]}$ Flat dog-bone-shaped tensile specimens were machined using an electrical discharge machine, with the gage length, gage width, and thickness of $77,6.35$, and $1.5 \mathrm{~mm}$, respectively. In-situ neutron diffraction was conducted with a time-of-flight method using SMARTS at the Los Alamos Neutron Science Center. The tensile loading was carried out by a servohydraulic load-frame positioned in the diffraction cave. The experiment was set up such that the loading axis was at a $45 \mathrm{deg}$ angle to the incident neutron beam, and the two detector banks were at \pm 90 deg to the incident beam. With this setting, the lattice strains in the longitudinal direction and the transverse direction were determined using the $\pm 90 \mathrm{deg}$ detector banks, respectively. The loading scheme was programmed to increase the applied load stepwise, with a few unloading events executed to detect the residual lattice strains. The measured diffraction spectra were processed with Rietveld refinement by using the GSAS software package. ${ }^{[29,30]}$ For the textured materials used in this study, peak profile fitting was implemented with spherical harmonics to take the texture into account during the Rietveld refinement, from which the average lattice parameters as well as the weight fraction of phases were determined, and the lattice strains were calculated as

Table I. Chemical Compositions (Weight Percent) of TRIP 590 and TRIP 780

\begin{tabular}{lcccccc}
\hline & $\mathrm{C}$ & $\mathrm{Mn}$ & $\mathrm{Si}$ & \multicolumn{1}{c}{$\mathrm{P}$} & $\mathrm{Al}$ & $\mathrm{S}$ \\
\hline TRIP 590 & 0.18 & 1.52 & 0.39 & 0.15 & 0.1 & 0.005 \\
TRIP 780 & 0.20 & 2.21 & 0.07 & 0.013 & 1.41 & 0.002 \\
\hline
\end{tabular}

$$
\varepsilon_{\text {lattice }}=\frac{a-a_{0}}{a_{0}}
$$

where $a_{0}$ is the lattice parameter of the reference state, and $a$ is the lattice parameter under load.

The microstructures of TRIP samples before and after tensile deformation were investigated with optical microscopes and TEM. The 2 pct nital solution was used to etch the specimens for optical observations. The TEM specimens were prepared using a twin-jet electrical polisher with the solution of 10 pct perchloric acid +90 pct ethanol at a temperature between $-20{ }^{\circ} \mathrm{C}$ and $-10^{\circ} \mathrm{C}$. The TEM observations were carried out using a Hitachi-800 microscope operating at $200 \mathrm{kV}$. The grain sizes were estimated according to ASTM E-112. The grain structures and phase morphologies were examined using TEM before and after deformation.

\section{RESULTS AND DISCUSSION}

Figure 1 shows the optical microstructures of TRIP 590 and TRIP 780 prior to mechanical tests. After the samples were etched, the ferrite appeared white, the bainite gray, and the RA black under optical microscope. One can see that ferrite is the main constituent in the TRIP 590, with approximately 10 pct RA (in volume fraction) in the sample. The RA grains were smaller than ferrite grains and mostly located in the grain boundaries of ferrite phase. In TRIP 780, besides ferrite phase, bainitic ferrite was found as one of the main constituents. However, the volume fraction of RA phase was much smaller in TRIP 780, compared to that in TRIP 590. The ferrite grain sizes of TRIP 590 and TRIP 780 are 10 and $\sim 7 \mu \mathrm{m}$, respectively. The ferrite grains appear equiaxed in both TRIP 590 and TRIP 780.

Figure 2 presents neutron diffraction patterns of TRIP 590 and TRIP 780 collected from the loading direction. The phases are identified as body-centeredcubic (bcc) and face-centered-cubic (fcc) in both steel samples. The fcc phase is the RA ( $\gamma$ phase), while the bcc phase could be a mixture of ferrite ( $\alpha$ phase) with possibly bainitic ferrite and martensite ( $\alpha^{\prime}$ phase), which could not be separated due to the low resolution of neutron diffraction. From the relative peak intensity, the weight fraction of RA in the as-received TRIP 590 was clearly higher than that in TRIP 780, due to the different thermal mechanical processes. In addition, one can see that the samples were textured, particularly for the bcc phases, because the relative intensity of the (211) peak was very high compared to that of the (110) peak.

Figure 3 shows the bright-field TEM images of TRIP 590 and TRIP 780 prior to mechanical tests. The main phase components of TRIP 590 were identified as ferrite and RA, with the bainite phase only being occasionally observed. The RA was estimated as $\sim 10$ pct in volume fraction. The ferrite grains in TRIP 590 showed equiaxed shape, but the RA mostly located in the grain boundaries of ferrite, although isolated RA was also found inside the ferrite grains (Figure 3(a)). The RA grains appeared baseball-bat shape. (Note that the circular cross section of RA was observed in some 

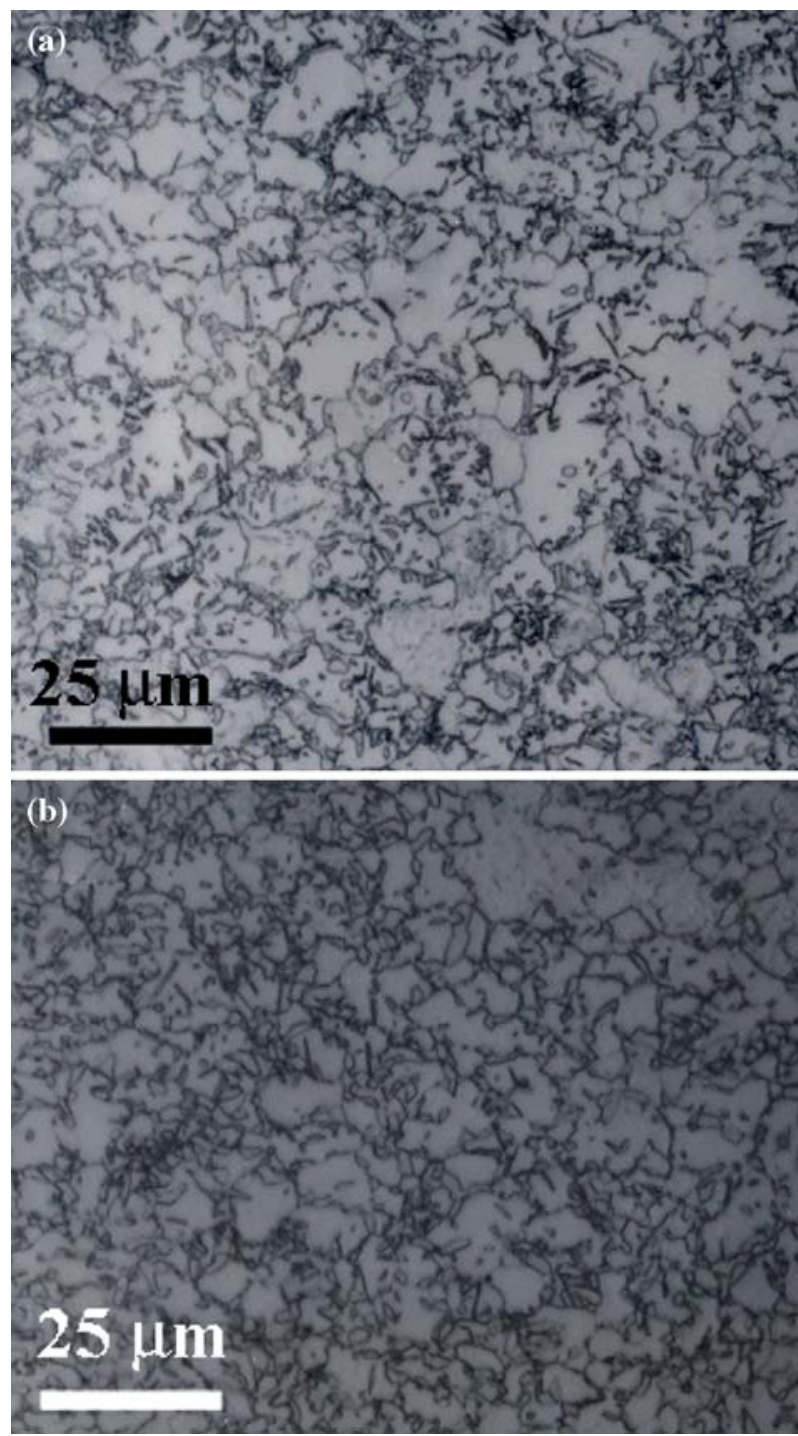

Fig. 1-Optical micrographs of (a) TRIP 590 steel and (b) TRIP 780 steel. The white phase was ferrite, and the RA was black. The ferrite grain sizes in TRIP 590 and TRIP 780 were $\sim 10$ and $\sim 7 \mu \mathrm{m}$, respectively.

grains with different orientations, Figure 3(a)). The length direction of RA is randomly orientated with respect to the sample coordinates. By contrast, TEM observation indicates that TRIP 780 was mainly composed of ferrite and bainite, with few RA observed. Figure 3(b) shows the TEM micrographs of the asreceived TRIP 780; a random mixture of ferrite and bainite (marked by $\alpha$ and B in Figure 3(b), respectively) was demonstrated. The volume fraction of bainite was estimated as 20 to 30 pct.

Figure 4(a) shows the true stress-strain curves of the TRIP 590 and TRIP 780 steels measured during in-situ neutron diffraction experiments. To ensure that the samples do not fracture during collection of neutron data, the measurements were switched from loadcontrolled mode to displacement-controlled mode after initial loading. The initial constant stress during neutron

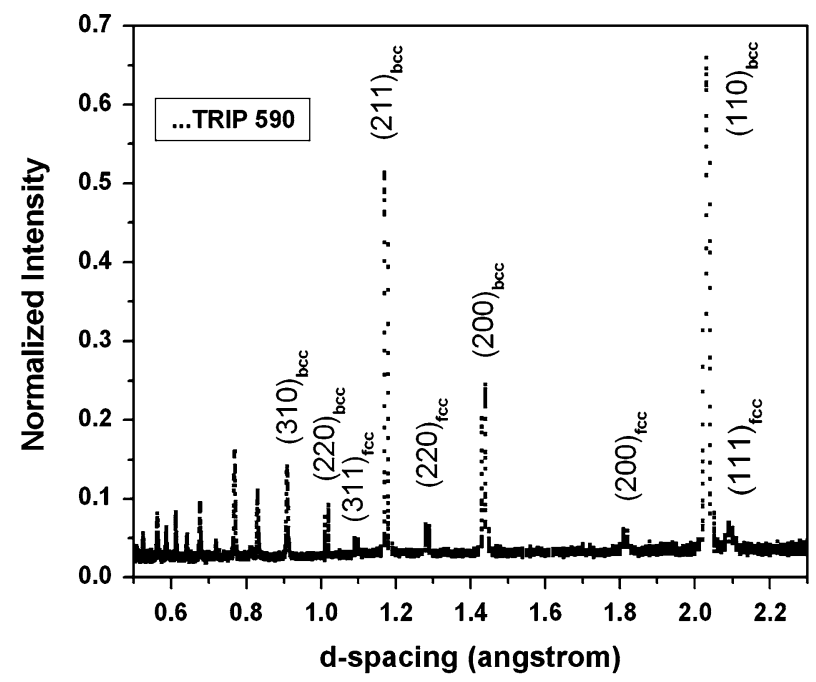

(a)

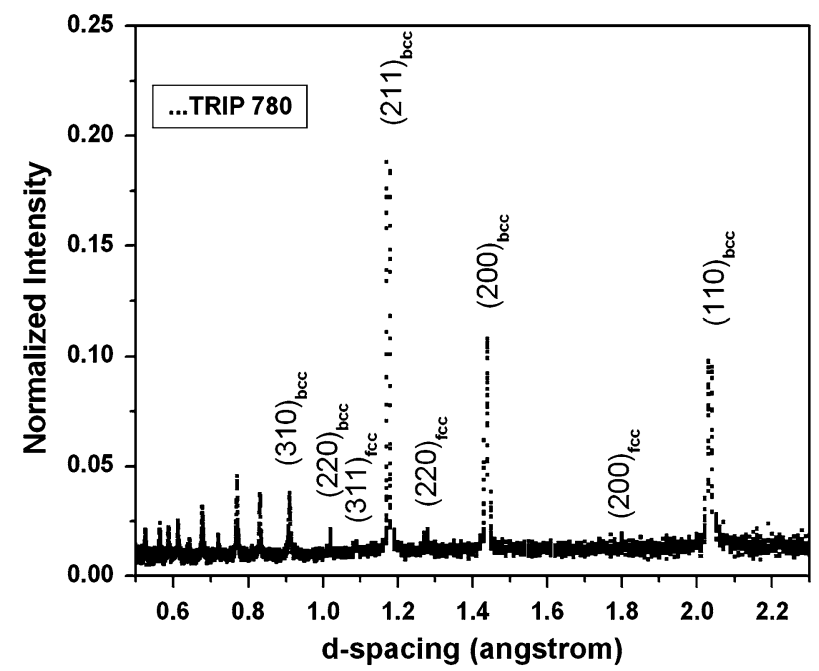

(b)

Fig. 2-Neutron diffraction spectra of (a) TRIP 590 and (b) TRIP 780. The patterns were obtained from the longitudinal direction of the samples. The peaks from RA can be readily identified in TRIP 590, while those from RA in TRIP 780 are barely above the background, indicating a smaller content.

data collection changed to small load drops in the curves due to the stress relaxation during the holding time at a constant strain. Several unloading episodes were implemented to measure the residual lattice strains. The curves in Figure 4 indicate that the 0.2 pct yield stress $\left(\sigma_{0.2}\right)$ of TRIP 590 is close to that of TRIP 780. TRIP 780 has a higher ultimate tensile stress with a tensile elongation to fracture of $\sim 14$ pct (engineering strain), much less than that of TRIP 590 ( $\sim 25$ pct engineering strain). Figure $4(\mathrm{~b})$ presents the normalized workhardening rate, $\frac{1}{\sigma} \frac{d \sigma}{d \varepsilon}$, of TRIP 590 and TRIP 780, respectively. One can see that the work-hardening rate of TRIP 780 is larger than that of TRIP 590, despite its lower tensile ductility as compared to that of TRIP 590 . This finding indicates that different hardening mechanisms exist in these TRIP steels. 

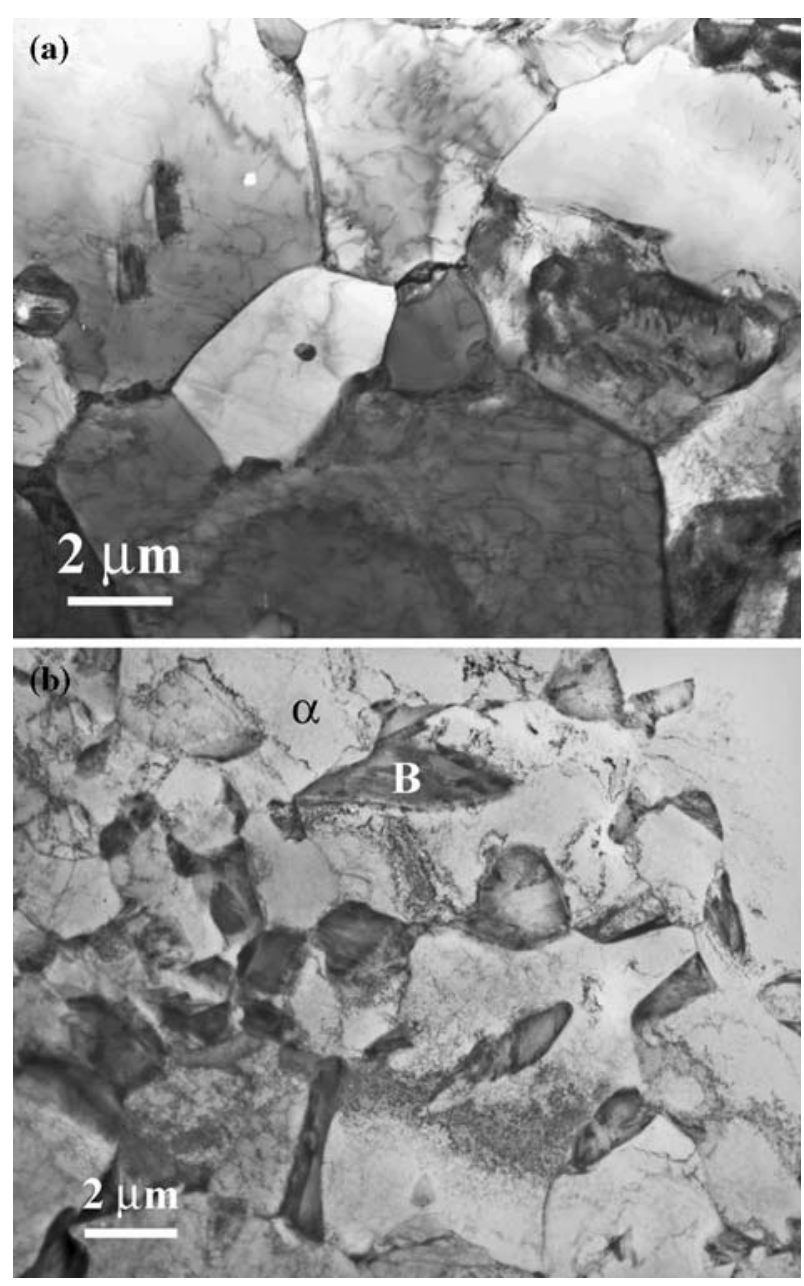

Fig. 3-(a) Bright-field TEM micrographs of TRIP 590 prior to tensile deformation: mainly two phases were present: ferrite and RA; the ferrite was equiaxed, but RA was baseball-bat shaped. (b) Bright-field TEM micrographs of TRIP 780 prior to tensile deformation: mainly two phases were present: ferrite and bainite, as identified by $\alpha$ and $\mathrm{B}$, respectively.

The lattice strain evolutions in the loading direction of both RA (fcc) and ferrite (bcc) phases are presented in Figure 5. The proportional limit $\left(\sigma_{p}\right)$ and the macroscopic yield stress $\left(\sigma_{0.2}\right)$ are represented by horizontal dotted lines. The dashed line was extended from the linear response to illustrate the lattice strain deviation. To correlate the lattice strain evolution with the martensitic transformation, the weight fraction of the RA was also plotted in Figure 5.

The stress partition during tensile loading was reflected from the lattice strain evolution of the phases. It can be seen, as the applied stress increases, that the lattice strain of TRIP 590 can be roughly divided into a three-stage evolution (Figure 5(a)).

Stage I. The first stage lies between $\sigma_{p}$ and $\sigma_{0.2}$, where the lattice strain of the fcc phase started to deviate from the straight line to large values after $\sigma_{p}$ was reached, while the lattice strain of the bcc phase deviated to small strains (going upward). The macroscopic yield stress, $\sigma_{0.2}$, was not reached. The deviation from linearity

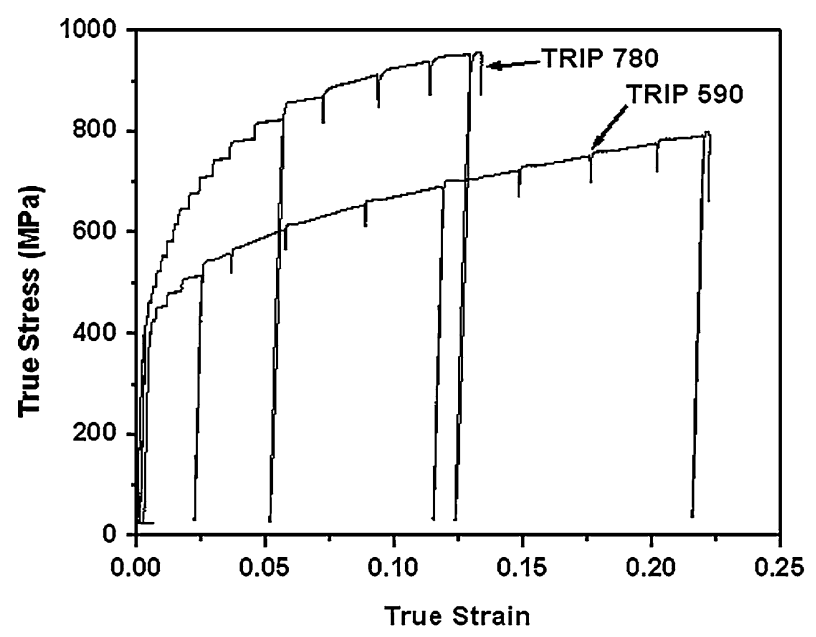

(a)

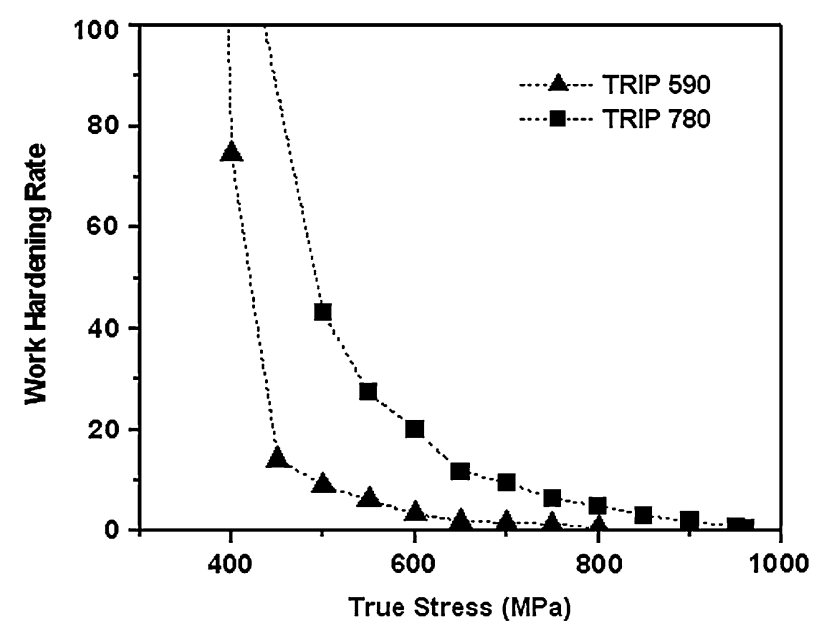

(b)

Fig. 4-(a) True stress-strain curves of TRIP steel 590 and TRIP steel 780, measured during in-situ neutron diffraction experiments. (b) The normalized work-hardening rate, $\frac{1}{\sigma} \frac{d \sigma}{d \varepsilon}$, of TRIP 590 and TRIP 780 .

indicates that yielding took place at the microscopic level. This behavior was a result of the strength difference of the phases. The yield stress of ferrite is lower than those of RA and martensite, i.e., $\sigma_{y}^{\alpha}<\sigma_{y}^{R A}<\sigma_{y}^{M}{ }^{[31]}$ Thus, the soft ferrite phase yields first, and plastically deforms, i.e., microyielding takes place in ferrite, but less plastic deformation is in the RA. Moreover, the strain-induced martensitic transformation did not yet start (as demonstrated by the constant austenite fraction). Due to the microyielding of ferrite, the stress applied to these phases began to redistribute; in other words, the stress shifted from ferrite to RA. With the ferrite phase plastically deforming, the austenite carries an increased share of load. As a result of the load transfer, a tensile internal stress developed in austenite in the loading direction, while compressive internal stress built up in the bcc phase. The microyielding of ferrite revealed by lattice strain was supported by our TEM observations. Figure 6(a) shows the TEM micrographs of a TRIP 590 sample after tensile 


\section{Austenite Weight Fraction}

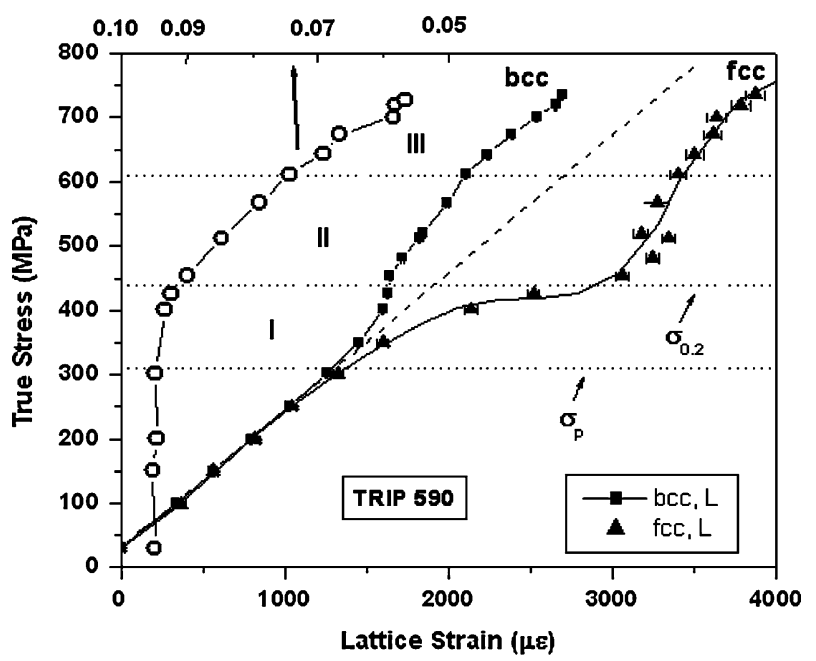

(a)

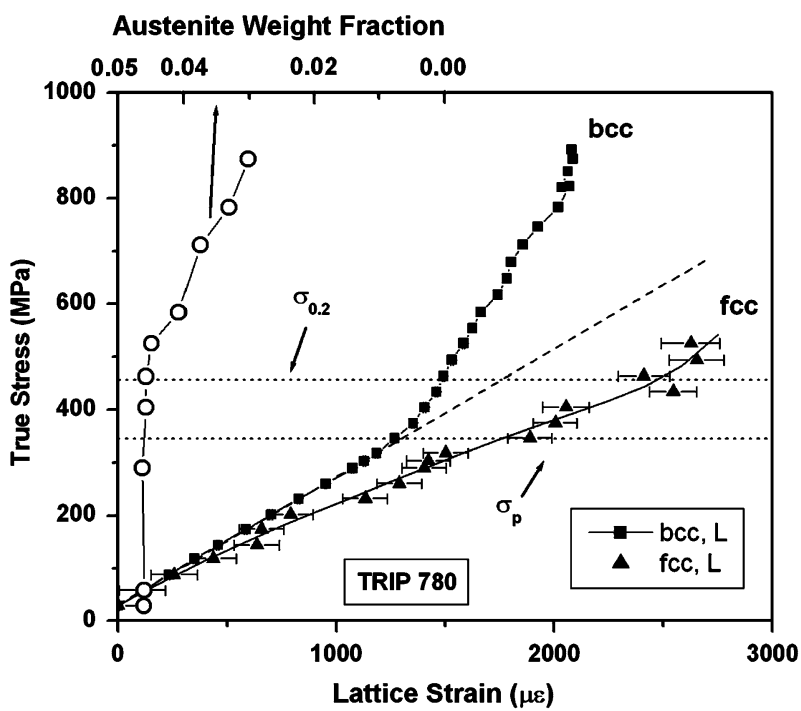

(b)

Fig. 5-The lattice strain evolution in the loading direction (L) of fcc phase (RA) and bcc phase during the in-situ neutron measurements in (a) TRIP 590 steel and $(b)$ TRIP 780 . The weight fraction of RA (open symbols) was plotted to correlate to the lattice strain evolution. Note that the bcc phase in TRIP 590 refers to the sum of ferrite and martensite phases, whose peaks overlapped, after the martensitic transformation was induced, while it refers to ferrite and bainite in TRIP 780 .

deformation to 0.15 pct plastic strain (where $\sigma_{T}=$ $412 \mathrm{MPa}$ ). One can see that dislocations were produced in one ferrite grain, while its sister grain was nearly dislocation free. This finding indicates that the strain was fairly high locally in some grains, but the martensitic transformation has not happened yet in the RA grain.

Stage II. After the applied stress exceeded the macroscopic yield stress $\left(\sigma_{0.2}\right)$, the RA started to yield, and the strain-induced martensitic transformation was triggered ${ }^{[32,33]}$ Because the newly-forming martensite is of bcc structure and its peaks overlapped with the existing bcc peaks, i.e., the ferrite, they were treated as a
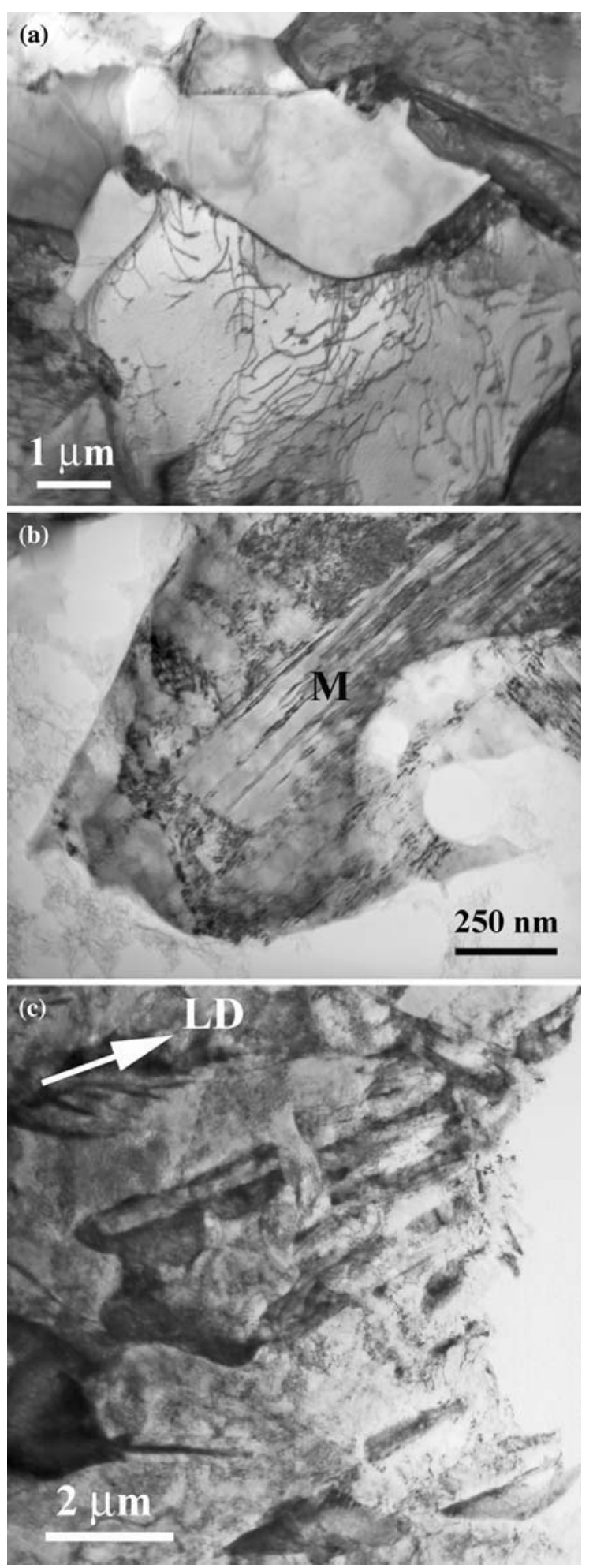

Fig. 6-Bright-field micrographs of TRIP 590 after a plastic deformation of 0.15 pct: $(a)$ dislocations were generated in ferrite grains; $(b)$ bright-field TEM micrograph of TRIP 590 after a tensile deformation of $\sim 8$ pct, showing the martensitic transformation within RA; and $(c)$ bright-field TEM micrographs of TRIP 590 after tensile deformation to fracture: both the ferrite and RA were elongated along the LD.

single phase in the refinement and collectively called the bcc phases in Figure 5. Note that the martensite phase is an even harder phase compared to the RA. Thus, the 

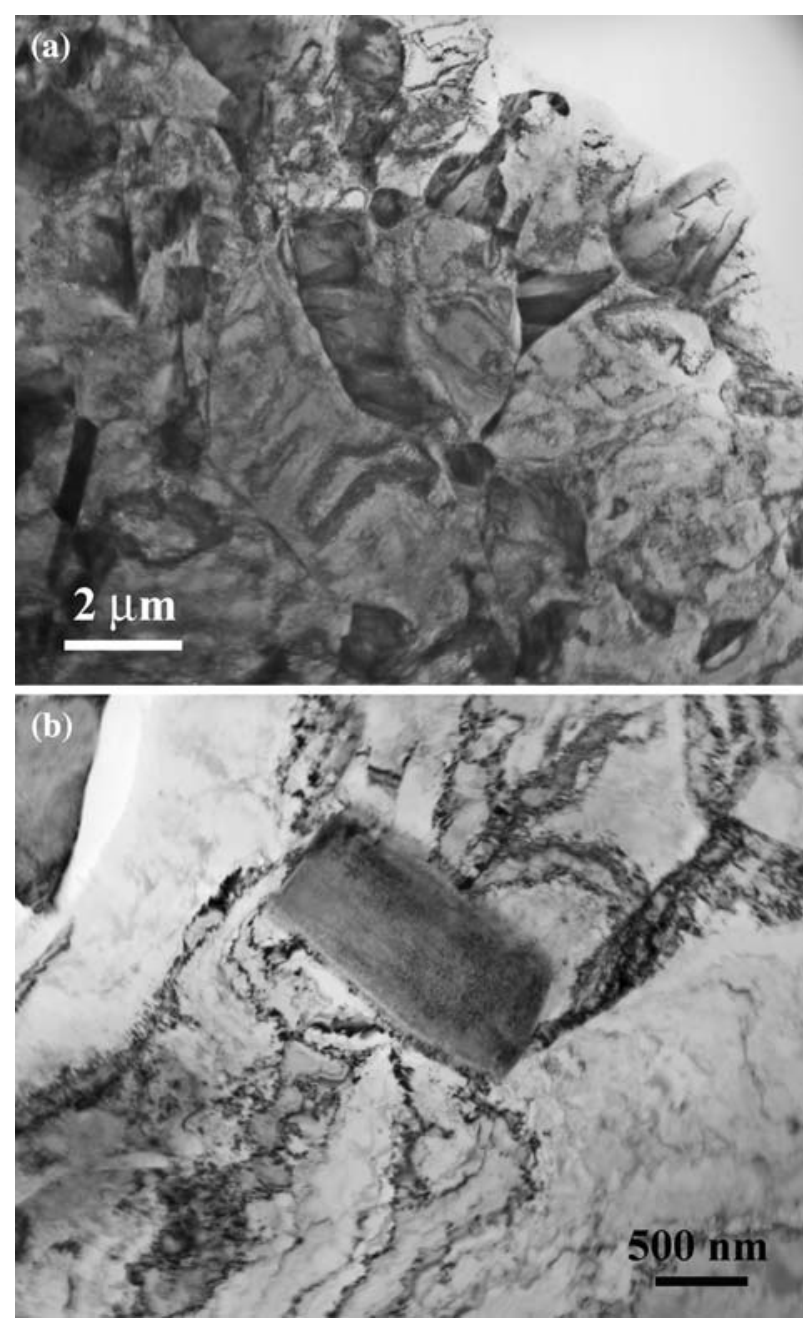

Fig. 7-Bright-field TEM micrographs of TRIP 780 after tensile deformation to fracture (13 pct true strain): (a) a low-magnification image showing the plastically deformed ferrite and bainite with little deformation; and $(b)$ dislocations generated and piled around a hard bainite particle.

load transfers back to the bcc phases (actually to martensite phase) from the austenite.

In this stage, the ferrite continued to deform plastically; however, as a result of stress sharing by martensite, the overall lattice strain of the bcc phases started to increase, and the development of the lattice strain in RA slowed (turning upward) due to its yielding. The weight fraction of the RA as a function of applied true stress was also plotted in Figure 5(a), in which the martensitic transformation was clearly shown. In stage II, the obvious increase in lattice strain in the bcc phase indicates that the bcc phase becomes subjected to the increased load partitioning, and the work hardening was mainly contributed from this phase as the martensitic transformation occurred in the fcc phase (which led to a lesser work-hardening rate in the fcc phase). The hardening from martensitic transformation was also found via TEM observation. Figure 6(b) shows a brightfield TEM micrograph of TRIP 590 after tensile deformation to $\sim 8$ pct true strain; one can see that part of the RA has transformed into needlelike martensite. The martensite needles aligned in the direction of the RA length direction.

Stage III. After the applied stress approached $\sim 610 \mathrm{MPa}$, the lattice strains showed a slightly different behavior compared to stage II. As the austenite weight percent continued to drop with increasing stress, the lattice strains of bcc phases showed a trend of continuing increase, indicating the hardening of the bcc phases. Thus, the work-hardening rate in bcc is maintained, even though it is different from what was found in stage I (because the newly-formed martensite carried the load). However, the lattice strain of the fcc phase (austenite) appeared to increase as well. This finding indicates that the work-hardening rate resumes in the fcc phase in this stage due to the completion of martensitic transformation, which indicates that the austenite was also hardened and participated in the load sharing. Several factors could contribute to the austenite hardening. (1) The density of defects such as dislocations could increase in the austenite grains during deformation. Our statistics from TEM indicate that the RA grains were stretched along their length direction by 12 pct on average after deformation, which could increase the dislocation density in RA. (2) As the martensitic transformation occurred inside RA, as observed in Figure 6(b), the RA could be strengthened by the reduction of its effective grain size. (3) During the martensitic transformation, the enrichment of carbon and other elements in RA could effectively harden the RA. ${ }^{[34]}$ Figure 6(c) shows the bright-field TEM micrographs of TRIP 590 after tensile deformation to fracture, with a true strain $\varepsilon_{p}=22$ pct. One can see that the ferrite elongated along the loading direction (LD) and the baseball-bat-shaped RA was aligned with the loading direction.

The lattice strain evolution of TRIP 780 was different from that in TRIP 590 (Figure 5(b)). Due to the small volume fraction, a large error bar was observed for the lattice strain of RA. In addition, the lattice strain of RA exhibited a linear relationship with respect to applied true stress; only a slight nonlinearity appeared to emerge as the applied stress exceeded $\sigma_{0.2}$. Thus, the stress partition from RA was insignificant, as compared to TRIP 590. For bcc phases, the lattice strain went upward almost linearly, except the last few data points, but never bent toward higher strain as observed in TRIP 590. It has been demonstrated that the TRIP 780 contains a significant fraction of bainite phase (20 to 30 vol pct). Because the strength of bainite is much higher than that of ferrite, the stress partition thus mainly occurs between ferrite and bainite phases. In other words, the bainite remained elastic even after the ferrite phase yielded, and the stress transferred from ferrite to bainite. The linearity of bcc phases indicates that the composite lattice strains of ferrite and bainite were proportional to the applied true stress. As a result, the slowing of lattice strain in ferrite was compensated by the lattice strain of bainite, and the overall lattice strain of bcc phases followed a linear increase with applied stress. A small part of load could also go to RA and martensite, but because only $\sim 1.5 \mathrm{wt}$ pct 
transformed (from 4.5 to 3 wt pct, Figure 5(b)), the role of martensitic transformation in TRIP 780 was limited.

The stress partition between ferrite and bainite was also evidenced from the microstructure studies. Figure 7 shows the TEM micrographs of TRIP 780 after tension to fracture, where the true strain $\varepsilon_{T}=13$ pct. As shown in Figure 7(a), one can see that dislocations were produced in ferrite. However, little plastic deformation was experienced in bainite as the bainite phase maintained its original shape. Figure 7(b) shows the scenario that a high density of dislocations were generated in ferrite phase and concentrated around the bainite particles, but no sign of permanent deformation occurred in the bainite particle. This finding suggests that the plastic deformation was overwhelmingly concentrated in ferrite, but the bainite phase remained elastic. As a result, the bainite carried an increased share of the load.

A critical criterion of TRIP steel design and processing is to improve its energy absorption capacity, which requires an optimized combination of tensile strength and uniform tensile ductility. Maintaining a high workhardening rate is known as the key parameter to sustaining a uniform tensile deformation. In Figure 6, we demonstrated a higher work-hardening rate in TRIP 780 than TRIP 590, but the tensile elongation of the TRIP 780 was, on the contrary, less than that of TRIP 590 (14 vs 25 pct). As revealed by TEM in Figure 7, a severe stress concentration built up at the phase interface between the nondeforming bainite phase and ferrite due to the remarkable dislocation pileup. The stress concentration inevitably entailed decohesion of bainite from the ferrite matrix, leading to a sample failure at a smaller strain in TRIP 780, despite the apparent workhardening rate. Instead, the hardening of the structure in TRIP 590 was achieved by strain-induced martensitic transformation. The deformability of RA provided necessary accommodation between phases, such that the uniform deformation could continue with the martensitic transformation.

\section{SUMMARY}

In summary, we have demonstrated the hardening process via stress partition as well as the microstructural evolutions of TRIP steels. From the stress partition investigated by in-situ neutron diffraction, the apparent load transfer from austenite to the strain-induced martensitic reinforced the sample, and a higher tensile elongation was observed in TRIP 590, which contains a higher fraction of RA. In TRIP 780, with less austenite fraction, the contribution from martensitic transformation was limited. The stress partition mainly took place between the soft ferrite and hard bainite phase. Even with a higher work-hardening rate, the stress concentration in TRIP 780 between the bainite phase and the ferrite matrix resulted in smaller plasticity. Through neutron scattering coupled with TEM observations, the micromechanical processes of individual phases could be clearly revealed such that their contributions were evaluated. The observations provide a mechanistic basis for their macroscopic property.

\section{ACKNOWLEDGMENTS}

This work was supported by the NSF Major Research Instrumentation (MRI) Program (Grant No. DMR-0421219) and the NSF International Materials Institutes (IMI) program (Grant No. DMR-0231320). One of the authors (XLW) acknowledges support by the Division of Materials Sciences and Engineering, Office of Basic Energy Sciences, United States Department of Energy, under Contract No. DE-AC05-00OR22725 with UT-Battelle, LLC. This research was sponsored by the United States Department of Energy, Assistant Secretary for Energy Efficiency and Renewable Energy, Office of Freedom CAR and Vehicle Technologies, as part of the Automotive Light Weighting Materials Program, under Contract No. DE-AC05-00OR22725 with UT-Battelle, LLC.

\section{REFERENCES}

1. J. Mahieu, J. Maki, B.C. De Cooman, and S. Claessens: Metall. Mater. Trans. A, 2002, vol. 33A, pp. 2573-80.

2. I.B. Timokhina, P.D. Hodgson, and E.V. Pereloma: Metall. Mater. Trans. A, 2007, vol. 38A, pp. 2442-54.

3. E. Jimenez-Melero, N.H. van Dijk, L. Zhao, J. Sietsma, S.E. Offerman, J.P. Wright, and S. van der Zwaag: Acta Mater., 2007, vol. 55, pp. 6713-23.

4. X.D. Wang, B.X. Huang, L. Wang, and Y.H. Rong: Metall. Mater. Trans. A, 2008, vol. 39A, pp. 1-7.

5. P.J. Jacques, Q. Furnemont, S. Godet, T. Pardoen, K.T. Conlon, and F. Delannay: Phil. Mag., 2006, vol. 86, pp. 2371-92.

6. P.J. Jacques: Curr. Opin. Solid State Mater. Sci., 2004, vol. 8, pp. 259-65.

7. M.A. Meyers and K.K. Chawla: Mechanical Metallurgy: Principles and Applications, Prentice-Hall, Englewood Cliffs, NJ, 1984, p. 355.

8. P.J. Jacques, Q. Furnemont, F. Lani, T. Pardoen, and F. Delannay: Acta Mater., 2007, vol. 55, pp. 3681-93.

9. H.K.D.H. Bhadeshia: ISIJ Int., 2002, vol. 42, pp. 1059-60.

10. P.J. Jacques, J. Ladrière, and F. Delannay: Metall. Mater. Trans. $A, 2001$, vol. 32 A, pp. 2759-68.

11. D. Wu and Z. Li: ISIJ Int., 2006, vol. 46, pp. 1059-66.

12. W.C. Jeong, D.K. Matlock, and G. Krauss: Mater. Sci. Eng. A, 1993, vol. 165, pp. 1-8.

13. H. Su, W.D. Gunawadarna, A. Tuling, and B. Mintz: Mater. Sci. Technol., 2007, vol. 23, pp. 1357-66.

14. F. Perrard and C. Scott: ISIJ Int., 2007, vol. 47, pp. 1168-77.

15. N. Jia, R.L. Peng, Y.D. Wang, G.C. Chai, S. Johansson, G. Wang, and P.K. Liaw: Acta Mater., 2006, vol. 54, pp. 3907-16.

16. D.K. Balch and D.C. Dunand: Acta Mater., 2006, vol. 54, pp. $1501-11$

17. M.A.M. Bourke, R. Vaidyanathan, and D.C. Dunand: Appl. Phys. Lett., 1996, vol. 69, pp. 2477-79.

18. P. Sittner, P. Lukáš, V. Novak, M.R. Daymond, and G.M. Swallowe: Mater. Sci. Eng. A, 2004, vol. 378, pp. 97-104.

19. S. Wroński, A. Baczmański, R. Dakhlaoui, C. Braham, K. Wierzbanowski, and E.C. Oliver: Acta Mater., 2007, vol. 55, pp. 6219-33

20. M.L. Young, J.D. Almer, M.R. Daymond, D.R. Haeffner, and D.C. Dunand: Acta Mater., 2007, vol. 55, pp. 1999-2011.

21. G.J. Fan, L.F. Fu, Y.D. Wang, Y. Ren, H. Choo, P.K. Liaw, G.Y. Wang, and N.D. Browning: Appl. Phys. Lett., 2006, vol. 89, pp. 101918-101920. 
22. K.X. Tao, J.J. Wall, H.Q. Li, D.W. Brown, S.C. Vogel, and H. Choo: J. Appl. Phys., 2006, vol. 100, pp. 1235151-57.

23. J. Zrník, O. Stejskal, Z. Nový, P. Hornak, and M. Fujda: Mater. Sci. Eng. A, 2007, vol. 462, pp. 253-58.

24. O. Muránsky, P. Lukáš, J. Zrník, and P. Sittner: Physica B, 2006, vol. 385 , pp. $587-89$

25. W. Bleck and I. Schael: Steel Res., 2000, vol. 71, pp. 173-78.

26. K. Tao, H. Choo, H. Li, B. Clausen, J.E. Jin, and Y.K. Lee: Appl. Phys. Lett., 2007, vol. 90, pp. 1019111-13.

27. E.C. Oliver, P.J. Withers, M.R. Daymond, S. Ueta, and T. Mori: Appl. Phys. A, 2002, vol. 74, pp. 1143-45.

28. H.N. Han, C.G. Lee, C.S. Oh, T.H. Lee, and S.J. Kim: Acta Mater., 2004, vol. 52, pp. 5203-14.
29. A.C. Larson and R.B. von Dreele: LAUR 86-748 Report, Los Alamos National Laboratory, Los Alamos, NM, 1986.

30. H.M. Rietveld: J. Appl. Cryst., 1969, vol. 2, pp. 65-71.

31. Y. Tomota, H. Tokuda, Y. Adachi, M. Wakita, N. Minakawa, A. Moriai, and Y. Morii: Acta Mater., 2004, vol. 52, pp. 5737-45.

32. J. Zrník, O. Muránsky, P. Lukáš, P. Sittner, and Z. Nový: Mater. Sci. Forum, 2005, vol. 502, pp. 339-44.

33. R. Vaidyanathan, M.A.M. Bourke, and D.C. Dunand: Acta Metall., 1999, vol. 47, pp. 3353-66.

34. J. Huang, S.C. Vogel, W.J. Poole, M. Militzer, and P.J. Jacques: Acta Mater., 2007, vol. 55, pp. 2683-93. 